\title{
Plasma Triglyceride Metabolism in Thyroid Disease
}

\author{
Esko A. Nikkm̈̈ and Matti KekKI \\ From the Third Department of Medicine, University Central Hospital, \\ Helsinki 29, Finland
}

\begin{abstract}
A B S T R A C T Plasma endogenous triglyceride transport kinetics were determined in 16 hyperthyroid and in 12 hypothyroid patients and the results compared with those of euthyroid control subjects. In addition, the removal of exogenous particulate fat (Intralipid; Vitrum, Sweden) from the circulation and the postheparin plasma lipolytic activity (PHLA) were studied in these patients for further characterization of the alterations of plasma triglyceride metabolism in thyroid disease.
\end{abstract}

In thyrotoxicosis the average plasma triglyceride level was slightly but significantly increased above that of control subjects. This change was associated with augmented production of triglycerides whereas the mean fractional removal rate was not different from normal. There was a significant linear correlation between the concentration and turnover rate of plasma triglycerides in both hyperthyroid and euthyroid subjects but the concentration/turnover rate ratio was less in the former group suggesting that the efficiency of removal of triglycerides from the circulation was improved in thyroid hyperfunction. The elimination of intravenously administered particulate fat occurred more rapidly in untreated hyperthyroid patients than in euthyroid control subjects. The mean PHLA was also above normal in thyrotoxicosis. Upon adequate treatment of the hyperthyroid state the fasting plasma triglyceride concentration was further increased.

Hypothyroid patients showed another pattern of alteration of triglyceride kinetics. The synthesis of plasma triglycerides was normal but the fractional removal of both endogenous and exogenous triglycerides was markedly reduced and this change seems to account for the hypertriglyceridemia associated with thyroid hypofunction. The plasma PHLA was also clearly decreased in the hypothyroid state.

Plasma FFA and glycerol levels were increased in hyperthyroidism and plasma FFA was slightly de-

Received for publication 17 January 1972 and in revised form 3 April 1972. creased in hypothyroid patients, but these variables were not significantly correlated with any parameter of triglyceride metabolism.

Endogenous triglyceride turnover rate was significantly correlated with serum protein-bound iodine (PBI) and T3 uptake in thyrotoxicosis but not in hypothyroidism. Removal of exogenous fat was not related to postheparin plasma lipolytic activity but the fractional endogenous triglyceride transport showed a highly significant relationship to this lipase activity in a mixed group of hyper- and hypothyroid patients.

The results suggest that thyroid hormones control both production and removal of plasma triglycerides. Different mechanisms for these interactions are considered.

\section{INTRODUCTION}

It is not known whether thyroid hormones play any role in the regulation of plasma triglyceride (TG) ${ }^{1}$ concentration and transport, and relatively few studies have been carried out on the alterations of triglyceride and very low density lipoprotein (VLDL) metabolism in clinical thyroid disease. This is in sharp contrast to the situation in cholesterol metabolism, which is well explored in both hyper- and hypothyroidism and is generally believed to undergo typical and consistent changes in both conditions. The plasma triglyceride concentration may be completely normal in hypothyroidism $(1,2)$, but usually it is moderately elevated (2-5) and occasional cases of gross hyperlipemia have been reported in myxedema $(1,2,6)$. The increase has been attributed to a low lipoprotein lipase (LPL) activity, since it has been shown that the postheparin plasma lipolytic activity (PHLA) is inversely corre-

\footnotetext{
${ }^{1}$ Abbreviations used in this paper: LDL and VLDL, low density and very low density lipoprotein, respectively; LPL, lipoprotein lipase; PBI, protein-bound iodine; PHLA, lipolytic activity of postheparin plasma; $\mathrm{RBW}$, relative body weight; $T 3$, triiodothyronine uptake by resin; $T G$, triglyceride.
} 
lated with the plasma triglyceride level in patients with myxedema $(5,7)$. In spite of this LPL deficiency, the hypertriglyceridemia associated with hypothyroidism is not of the fat-induced type (3). In thyroid hyperfunction, both decreased $(4)$ and normal $(5,8)$ plasma triglyceride mean levels have been observed. In the only kinetic study published so far, Sandhofer, Sailer, and Braunsteiner (9) found decreased conversion of plasma FFA into endogenous plasma triglyceride in patients with hyperthyroidism and this change was believed to account for the decreased plasma triglyceride levels. A slightly decreased PHLA has also been reported in thyrotoxicosis (5).

The present study was undertaken in order to provide more systematic data on the alterations of plasma triglyceride concentration and transport in clinical disorders of thyroid function. It was revealed that both hyper- and hypothyroidism are characterized by rather specific patterns of disturbed triglyceride transport kinetics. These data also serve as an example of how kinetic analysis may be applied in resolving the basic mechanisms of hypertriglyceridemia.

\section{METHODS}

Patient series. The study was originally carried out in 16 patients with clinically unequivocal hyperthyroidism and in 12 subjects suffering from definite thyroid hypofunction. Eight patients of the former group were restudied after treatment when they had achieved an euthyroid state. The somatic data and results of thyroid function tests are presented in Tables I and II. The diagnosis was based on characteristic history, clinical findings, serum protein-bound iodine (PBI), triiodothyronine uptake test (T3), and thyroidal uptake of radioiodine. In many instances additional determinations of serum total and free thyroxine and of urinary hydroxyproline excretion were made and these results further confirmed the diagnosis but they are not included in the tables. Of the hyperthyroid patients ten had typical Graves' disease and the remaining six had a toxic multinodular goiter. The hypothyroidism was in most instances caused by autoimmune thyroiditis, the diagnosis of which was based on high titer of thyroglobulin antibodies in serum or thyroid cytology, or both. In two cases the etiology of the hypothyroidism could not be traced.

Three of the patients had additional extrathyroidal diseases, which may have influenced the triglyceride metabolism (besides moderate overweight). These patients have not been excluded from the series but their results were omitted from statistical calculations. Patient No. 14 of thyrotoxic group had a newly detected mild nonketotic diabetes. Patient No. 24 of the hypothyroid series developed manifest diabetes $1 \mathrm{yr}$ after he was investigated for this study. Blood glucose had not been measured at that time but it is possible that the diabetes was already present then. Patient No. 26 was grossly obese and had latent diabetes.

Control series. Since it was difficult to carry out the complete study in adequately matched series of euthyroid subjects without other interfering diseases, several groups of subjects were used for comparison. All of them were euthyroid by the common clinical and laboratory criteria. The basic control series consisted of healthy normal volunteers, 18 men and 16 women, whose plasma triglyceride transport kinetics have been reported previously (10). This group served as a fairly well-matched control series for the hyperthyroid patients, but most of the hypothyroid subjects were more or less overweight postmenopausal females, which necessitated collection of another control group. For this comparison eight postmenopausal women were selected from our (unpublished) series of obese patients, in whom the

TABLE I

Clinical and Laboratory Data of 16 Cases of Untreated Hyperthyroidism

\begin{tabular}{|c|c|c|c|c|c|c|c|c|c|}
\hline No. & Initials & Sex & Age & RBW* & PBI & T3t & Cholesterol & 111-uptake & Diagnosis \\
\hline & & & & $\%$ & $\mu \mathrm{g} / 100 \mathrm{ml}$ & $\%$ & $m g / 100 m l$ & $\begin{array}{c}\text { per cent/ } \\
24 \mathrm{hr}\end{array}$ & \\
\hline 01 & M. F. & $\mathbf{F}$ & 22 & 111 & 11.0 & 178 & 155 & 83 & Toxic nodular goiter \\
\hline 02 & G. L. & $\mathbf{F}$ & 52 & 134 & 10.7 & 154 & 185 & 61 & Graves' disease \\
\hline 03 & E. S. & $\mathbf{F}$ & 37 & 100 & 16.4 & - & 156 & 84 & Graves' disease \\
\hline 04 & R. M. & $\mathbf{F}$ & 53 & 103 & 12.4 & 136 & 156 & - & Toxic nodular goiter \\
\hline 05 & S. M. & $\mathbf{F}$ & 70 & 116 & 11.4 & 145 & 205 & 49 & Toxic nodular goiter \\
\hline 06 & M. H. & $\mathbf{F}$ & 44 & 131 & 17.0 & 129 & 168 & 一 & Toxic nodular goiter \\
\hline 07 & A. $\mathbf{K}$. & $\mathrm{F}$ & 46 & 105 & 13.8 & 170 & 212 & - & Graves' disease \\
\hline 08 & K. H. & $\mathbf{M}$ & 22 & 71 & $>20.0$ & 177 & 180 & 88 & Graves' disease \\
\hline 09 & E. V. & F & 66 & 170 & 13.0 & 127 & 152 & - & Toxic nodular goiter, obesity \\
\hline 10 & E. $\mathbf{K}$. & $\mathrm{F}$ & 60 & 138 & 12.4 & 126 & 213 & 28 & Toxic nodular goiter \\
\hline 11 & K. L. & $\mathbf{M}$ & 32 & 125 & 18.5 & 187 & 127 & 70 & Graves' disease \\
\hline 12 & K. S. & M & 27 & 84 & 17.2 & 147 & 207 & 68 & Graves' disease \\
\hline 13 & A. U. & M & 63 & 83 & $>20.0$ & 167 & 127 & - & Graves' disease \\
\hline 14 & T. K. & $\mathbf{M}$ & 22 & 85 & 9.6 & 172 & 145 & 60 & Graves' disease, diabetes \\
\hline 15 & E. D. & $\mathbf{F}$ & 37 & 93 & 16.0 & 168 & 145 & 66 & Graves' disease \\
\hline 16 & L. N. & $\mathrm{F}$ & 22 & 124 & $>20.0$ & 200 & 150 & 83 & Graves' disease \\
\hline
\end{tabular}

* Reference 17.

‡ Normal range $90-115 \%$. 
TABLE II

Clinical and Laboratory Data of 12 Patients with Untreated Hypothyroidism

\begin{tabular}{|c|c|c|c|c|c|c|c|c|c|}
\hline No. & Initials & Sex & Age & RBW* & PBI & T3ł & Cholesterol & 121I-uptake & $\begin{array}{c}\text { Etiology of hypothyroidism; } \\
\text { other diseases }\end{array}$ \\
\hline & & & & $\%$ & $\mu g / 100 \mathrm{ml}$ & $\%$ & $m g / 100 m l$ & $\begin{array}{l}\text { per cent/ } \\
24 \mathrm{hr}\end{array}$ & \\
\hline 17 & T. P. & $\mathbf{M}$ & 48 & 132 & 1.0 & 85 & 473 & 7 & Autoimmune thyroiditis \\
\hline 18 & A. L. & $\mathrm{F}$ & 59 & 117 & 2.6 & 77 & 620 & 5 & Autoimmune thyroiditis \\
\hline 19 & M. Y. & $\mathbf{F}$ & 63 & 143 & 1.3 & 76 & 248 & - & Radioiodine therapy \\
\hline 20 & T. V. & $\mathbf{F}$ & 64 & 134 & 1.8 & 62 & 624 & 4 & Thyroidectomy \\
\hline 21 & S. $\mathrm{K}$. & $\mathrm{F}$ & 30 & 98 & 1.9 & 82 & 435 & 2 & Autoimmune thyroiditis \\
\hline 22 & M. $\mathrm{K}$. & $\mathbf{F}$ & 64 & 141 & 3.0 & 84 & 294 & 20 & Chronic lymphocytic thyroiditis \\
\hline 23 & A. P. & $\mathrm{F}$ & 58 & 101 & 2.5 & 73 & 341 & 6 & Idiopathic \\
\hline 24 & J. V. & M & 16 & 129 & 1.4 & 66 & 417 & - & Autoimmune thyroiditis, diabetes? \\
\hline 25 & R. L. & $\mathbf{M}$ & 40 & 125 & 3.9 & 92 & 317 & 4 & Autoimmune thyroiditis, diabetes? \\
\hline 26 & L. S. & $\mathrm{F}$ & 60 & 150 & 2.8 & 55 & 432 & 4 & Sarcoidosis, obesity, diabetes \\
\hline 27 & I. $\mathrm{P}$. & $\mathrm{F}$ & 58 & 109 & 2.0 & 78 & 700 & 3 & Idiopathic \\
\hline 28 & A. $\mathbf{K}$. & F & 58 & 119 & 3.0 & 78 & 300 & 12 & Chronic lymphocytic thyroiditis \\
\hline
\end{tabular}

* Reference 17.

$\ddagger$ Normal range $90-115 \%$.

plasma triglyceride turnover had been determined by a method identical to that used here for thyroid patients. For the Intralipid test a further control group of healthy normoglyceridemic volunteers was studied. Finally, "normal" controls for PHLA assay were partly laboratory personnel, partly patients with minor nonmetabolic disorders, and the normal values for plasma FFA and glycerol were obtained from hospital and laboratory personnel.

Experimental design. For the primary study all the thyroid patients were admitted to hospital and put on a standard diet containing $45 \%$ of calories as carbohydrate, $35 \%$ as fat, and $20 \%$ as protein. Calories were provided in an estimated amount of $35 \mathrm{cal} /$ day per $\mathrm{kg}$ for hyperthyroid and $25 \mathrm{cal} /$ day per $\mathrm{kg}$ for hypothyroid patients but adjustments were made to keep the patients' weight at a constant level. All patients were untreated for their thyroid disease when admitted to hospital and no drugs influencing either thyroid function or plasma lipid levels were administered before completion of the primary investigation. The lipid program was usually instituted during the 2nd wk of hospitalization and the complete set of studies consisted of determination of plasma triglyceride concentration and turnover rate, measurement of disappearance rate of i.v. fat emulsion (Intralipid test) and assays of plasma PHLA, FFA, and glycerol. The studies were usually carried out in this order on successive days, but in some instances the order was changed. Immediately after the last test day thyrostatic treatment, radioiodine therapy or thyroxine substitution was begun.

After completed treatment (surgery or radioiodine possibly followed by a short-term course of thyrostatic drugs) the thyrotoxic patients were placed on a routine follow-up schedule at the Endocrine Outpatient Unit of the hospital. When they had achieved completely normal thyroid function as evaluated by clinical and laboratory criteria all were asked to cooperate for a repeated triglyceride turnover study. Eight patients accepted the invitation and they were restudied 5-9 months after the first turnover measurement. At this time most of the subjects had been euthyroid for a minimum of 2-3 months and six were without any medication, but two were still receiving $15 \mathrm{mg}$ of methimazole per day. Four had been treated by surgery and the other four with radioiodine.

Measurement of plasma triglyceride turnover. The turnover rate was determined by the endogenous glycerol $-{ }^{3} \mathrm{H}$ labeling technique originally described by Farquhar, Gross, Wagner, and Reaven (11). In this method the plasma triglyceride is pulse-labeled in vivo with glycerol-2- ${ }^{3} \mathrm{H}$ and the fractional rate of disappearance of triglyceride radioactivity is followed for $10 \mathrm{hr}$. The total amount of triglyceride transported through the plasma pool per unit time (production rate) is then obtained as a product of fractional removal and pool size. The validity and reliability of the method have been thoroughly discussed $(10,11)$ but they have also been questioned $(12,13)$. The method implies that the fractional rate of efflux of triglyceride molecules from the circulation is approximated by the descending slope of the triglyceride radioactivity curve. This is true only if the injected labeled glycerol is incorporated into plasma triglycerides within a relatively short period of time and there is no quantitatively significant cycling of the label through pools (triglyceride or any other precursor pool) with a slower turnover. Conclusive evidence for the validity of this assumption is difficult to obtain, but substantial support for it has been given by a few reinfusion experiments (11) and, indirectly, by the close similarity of results with those derived from an independent nontracer method of measuring plasma triglyceride turnover (14). As pointed out previously (15) the location of the label in the 2-position $\mathrm{H}$-atom of glycerol makes the recycling minimal since this hydrogen is transferred to NAD on metabolization of glycerol through pathways other than direct esterification with fatty acids. Thus, the specific activity of all those compounds where the ${ }^{3} \mathrm{H}$ from $\mathrm{NAD}^{3} \mathrm{H}$ is distributed will presumably be much less than that of esterified liver and plasma lipids and this minimizes the secondary reincorporation into plasma triglycerides. In this respect the glycerol-2- ${ }^{3} \mathrm{H}$ essentially differs from the ${ }^{14} \mathrm{C}$-labeled triglyceride precursors.

The decay of radioactivity was measured only for total plasma triglyceride without separation of different lipoprotein fractions. This was done deliberately to obtain the over- 
all transport rate of triglycerides through the plasma pool, even though it is evident that this is a composite function of a family of decay rates (low density lipoproteins [LDL] and subfractions of VLDL).

Details of the procedure have recently been described elsewhere (10). The subjects were fasted from the previous evening $(10 \mathrm{hr})$ and in the morning they received glycerol$2-{ }^{8} \mathrm{H}$ (Radiochemical Centre, Amersham, England, SA 200 $\mathrm{mCi} / \mathrm{mmole}$ ) as a rapid pulse injection into an antecubital vein. The average dose was $4 \times 10^{7} \mathrm{cpm}$. Blood samples for the determination of triglyceride radioactivity were withdrawn from 1 to $6 \mathrm{hr}$ at 30-min intervals and at 7, 8, 9, 10, and $24 \mathrm{hr}$. Fasting continued up to the $8 \mathrm{hr}$ sample. Plasma triglyceride concentration was determined from $0,2,4$, and $8 \mathrm{hr}$ samples.

Plasma was separated immediately by centrifugation and stored at $+4^{\circ} \mathrm{C}$ to the next day. For the determination of triglyceride radioactivity $2 \mathrm{ml}$ of each plasma sample was extracted with $25 \mathrm{ml}$ of chloroform-methanol mixture $(2: 1)$, $5 \mathrm{ml}$ of $0.5 \%$ saline was added, and the tube was shaken for $5 \mathrm{~min}$ and left overnight at $+4^{\circ} \mathrm{C}$. The two phases were then separated by centrifugation, and the lower chloroform layer was transferred to another tube and washed once with $5 \mathrm{ml}$ of a chloroform-methanol- $0.5 \%$ saline mixture $(3: 47$ : 50). After centrifugation the lower chloroform phase was taken into another tube, silicic acid was added and the tube was shaken for $10 \mathrm{~min}$. The solvent was filtered into a counting vial, and evaporated to dryness, PPO-toluene scintillation mixture was added and the radioactivity was counted in a Packard Tricarb liquid scintillation counter (Packard Instrument Co., Inc., Downers Grove, Ill.). The separation of triglyceride from other lipids and the recovery were checked by repeated parallel lipid fractionations with thinlayer chromatography. Radioactivity was plotted against time on a semilogarithmic scale and the curve was analyzed with a digital computer. The acceptable resolutions have been been described in a previous paper (10). As a general rule, all curves composed of clearly more than one exponential slope and cases where the triglyceride concentration showed a systemic rise or fall amounting more than $15 \%$ (from 2 to $8 \mathrm{hr}$ ) were rejected. Such a non-steady state occurred in one hyperthyroid patient (No. 10) before treatment and in another (No. 03) on control study.

The mean exponential descending slope was taken as the fractional turnover rate constant ( $k$, fraction per hour) of total endogenous plasma triglyceride. The total triglyceride turnover (production) rate (V) was then calculated from the formula $\mathrm{V}(\mathrm{mg} / \mathrm{hr} / \mathrm{kg})=k \times \mathrm{S} \times 0.45 \times \mathrm{b}$, where $\mathrm{S}$ is the mean concentration of plasma triglyceride $(\mathrm{mg} / 100 \mathrm{ml})$ in the four samples taken during the experiment. The factor 0.45 is based on the assumption that plasma volume represents the distribution space of triglyceride and forms $4.5 \%$

TABLE III

Plasma Triglyceride Transport Data in Hyperthyroid Patients before and after Treatment

\begin{tabular}{|c|c|c|c|c|c|c|c|}
\hline \multirow[b]{2}{*}{ No. } & \multicolumn{3}{|c|}{ Untreated } & & \multicolumn{3}{|c|}{ Treated } \\
\hline & Concentration & $\begin{array}{l}\text { Fractional } \\
\text { rate }\end{array}$ & $\begin{array}{l}\text { Turnover } \\
\text { rate }\end{array}$ & & Concentration & $\begin{array}{l}\text { Fractional } \\
\text { rate }\end{array}$ & $\begin{array}{l}\text { Turnover } \\
\text { rate }\end{array}$ \\
\hline & $m g / 100 \mathrm{ml}$ & $h r^{-1}$ & $m g / h r / k g$ & & $m g / 100 \mathrm{ml}$ & $h r^{-1}$ & $\mathrm{mg} / \mathrm{hr} / \mathrm{kg}$ \\
\hline 01 & 89 & 0.253 & 10.2 & & & & \\
\hline 02 & 164 & 0.161 & 9.6 & & 224 & 0.173 & 14.1 \\
\hline 03 & 55 & 0.245 & 6.1 & & $124^{*}$ & \multicolumn{2}{|c|}{ Unsuccessful } \\
\hline 04 & 135 & 0.258 & 15.1 & & & & \\
\hline 05 & 98 & 0.195 & 7.7 & & 105 & 0.126 & 5.4 \\
\hline 06 & 58 & 0.340 & 7.3 & & & & \\
\hline 07 & 100 & 0.252 & 11.4 & & & & \\
\hline 08 & 100 & 0.305 & 13.7 & & 213 & 0.175 & 16.7 \\
\hline 09 & 109 & 0.220 & 7.4 & & 283 & 0.224 & 19.6 \\
\hline 10 & $150^{*}$ & \multicolumn{2}{|c|}{ Unsuccessful } & & 162 & 0.210 & 13.0 \\
\hline 11 & 128 & 0.392 & 19.2 & & 194 & 0.228 & 17.7 \\
\hline 12 & 144 & 0.360 & 23.5 & & 119 & 0,280 & 15.0 \\
\hline 13 & 133 & 0.255 & 15.3 & & & & \\
\hline $14^{*}$ & 101 & 0.276 & 12.6 & & & & \\
\hline 15 & 122 & 0.417 & 22.9 & & & & \\
\hline 16 & 156 & 0.432 & 23.8 & & & & \\
\hline Mean & 113 & 0.292 & 13.9 & & 186 & 0.202 & 14.5 \\
\hline SD & 33 & 0.084 & 6.6 & & 63 & 0.049 & 4.6 \\
\hline \multicolumn{8}{|l|}{ Controls } \\
\hline Mean & 72 & 0.250 & 7.8 & $P \ddagger$ & $<0.05$ & NS & NS \\
\hline SD & 26 & 0.069 & 2.8 & & & & \\
\hline$P \S$ & $<0.001$ & NS & $<0.01$ & & & & \\
\hline
\end{tabular}

* Omitted from statistical calculations.

$\ddagger$ Significance of the difference before and after treatment.

$\S$ Significance of the difference between hyperthyroid and control groups. 
TABLE IV

Plasma Triglyceride Transport Data in Patients with Hypothyroidism

\begin{tabular}{lccc}
\hline & \multicolumn{2}{c}{ Plasma triglyceride } & \\
\cline { 2 - 3 } No. & Concentration & $\begin{array}{c}\text { Fractional } \\
\text { transport } \\
\text { rate }\end{array}$ & $\begin{array}{c}\text { Total } \\
\text { turnover } \\
\text { rate }\end{array}$ \\
\hline & $m g / 100 m l$ & $h r^{-1}$ & $m g / h r / k g$ \\
17 & 167 & 0.088 & 5.3 \\
18 & 148 & 0.059 & 3.5 \\
19 & 92 & 0.200 & 6.3 \\
20 & 111 & 0.165 & 6.6 \\
21 & 184 & 0.110 & 9.1 \\
22 & 194 & 0.195 & 13.2 \\
23 & 157 & 0.118 & 8.3 \\
$24 *$ & 233 & 0.147 & 12.7 \\
25 & 127 & 0.129 & 6.2 \\
$26 \ddagger$ & 292 & 0.162 & 15.8 \\
27 & 402 & 0.065 & 11.8 \\
28 & 182 & 0.174 & 12.5 \\
Mean & 176 & 0.130 & 8.3 \\
SD & 86 & 0.051 & 3.3 \\
$P \S$ & $<0.001$ & $<0.001$ & $\mathrm{NS}$
\end{tabular}

* Omitted from statistical calculation because of possible diabetes.

$\ddagger$ Omitted from statistical calculation because of slight diabetes.

$\S$ Significance of difference from control group.

of ideal body weight in a normal human subject. Since the plasma volume is less in excess adipose tissue than in the rest of the body, a correction factor, b, for overweight has been included in the formula. It is calculated from

$$
\mathrm{b}=\left(\frac{4500+\mathrm{a} \times \mathrm{c}}{100+\mathrm{c}}\right) / 45 \text {, }
$$

where a represents the plasma volume per $\mathrm{kg}$ adipose tissue and is $9.7 \mathrm{ml}$ for men and $10.8 \mathrm{ml}$ for women (16) and $\mathrm{c}$ is the excess (17) of relative body weight (RBW per cent -100 ). The influence of thyroid disease on the plasma volume is known to be relatively small (18) and therefore no correction for this was made. In some cases the plasma volume was determined with radioiodinated albumin, and good agreement with the calculated estimates was obtained.

Fractional removal of exogenous fat (Intralipid test). To assess the rate of elimination of exogenous fat administered intravenously as "chylomicron-like" particles, the Intralipid test of Boberg, Carlson, and Hallberg (19) was employed. Subjects were fasted overnight and were then given a $20 \%$ fat emulsion (Intralipid) as a rapid infusion into an antecubital vein. More uniform exogenous triglyceride concentrations at the end of lipid infusion were obtained by modifying the dosage from that described in the original paper (19). Thus, instead of the $0.1 \mathrm{~g}$ of fat per $\mathrm{kg}$ body weight given in the earlier study, a dose of $0.1 \mathrm{~g}$ fat per $\mathrm{kg}$ of ideal body weight plus $0.05 \mathrm{~g}$ per $\mathrm{kg}$ of excess body weight was administered. This dosage resulted in initial exogenous triglyceride plasma levels of $300-400 \mathrm{mg} / 100 \mathrm{ml}$. Blood samples were drawn at $10,15,20,25,30,40,50$, and $60 \mathrm{~min}$ after the infusion and plasma was separated by centrifugation. The infused lipid was separated from the endogenous lipoprotein-bound triglycerides by ultracentrifugation in a Spinco Model L2 (Spinco Div., Beckman Instruments, Inc., Palo Alto, Calif.) for $300,000 \mathrm{~g}$-min at a density of 1.006 . The concentration of floating triglyceride was plotted against time on a semilogarithmic scale, the descending slope was drawn manually, and the elimination rate constant was obtained in the usual way from $K=\ln 2 / \mathrm{t} \frac{1}{2}$ (per cent $/ \mathrm{min}$ ).

The postheparin plasma lipolytic activity $(P H L A)$. The PHLA was determined from plasma samples taken $10 \mathrm{~min}$ after i.v. injection of $0.2 \mathrm{mg} / \mathrm{kg}$ of heparin. The blood was kept in ice and centrifuged in the cold and the plasma was stored frozen until assayed, which usually occurred within 1 wk. Several earlier control studies had indicated that no decrease of lipolytic activity occurred during this time of storage. The activity was determined from duplicate samples by the method of Boberg and Carlson (20), which utilizes Intralipid as substrate. The activity was expressed as nmoles FFA released by $1 \mathrm{ml}$ of plasma per minute.

Analytical methods. Triglyceride was determined by the Technicon Autoanalyzer (Technicon Instruments Corp., Tarrytown, N. Y.) (21), plasma FFA and FFA released in the PHLA by a colorimetric method (22), and plasma glycerol by a fluorometric technique (23). All other data were obtained from the routine clinical laboratory.

\section{RESULTS}

Endogenous triglyceride transport. The individual triglyceride kinetic data are presented in Tables III and IV and in Fig. 1. In untreated thyrotoxicosis the

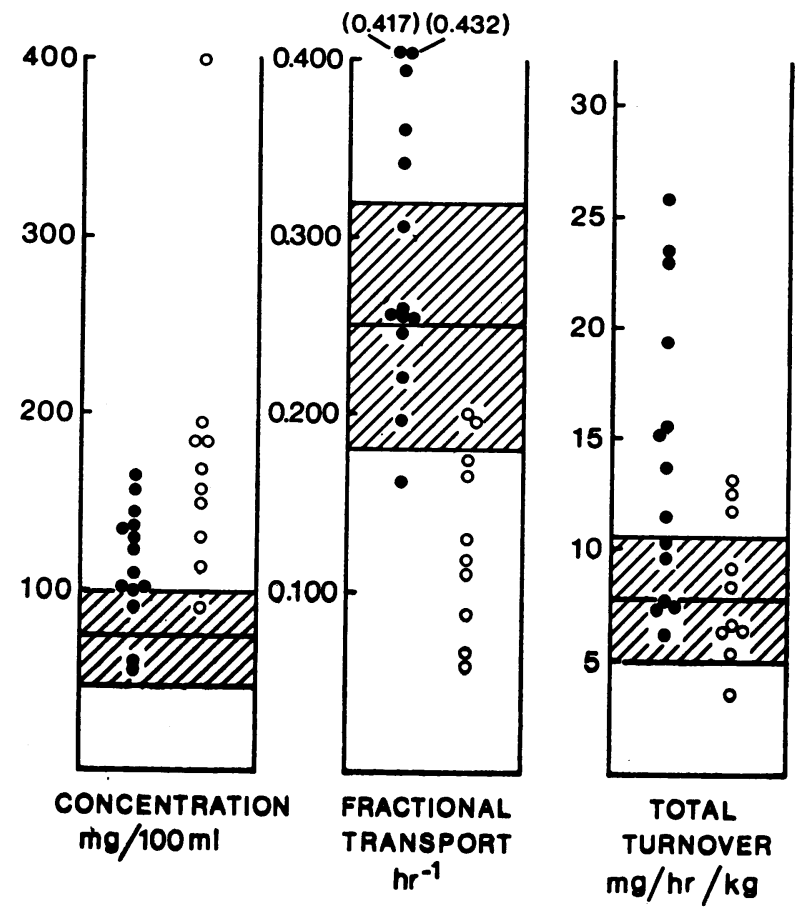

FIGURE 1 Concentration, fractional transport, and total turnover rate of plasma triglyceride (all fractions) in hyperthyroid (black dots) and hypothyroid (open dots) patients. The hatched area in each bar represents the mean \pm 1 SD of 34 healthy normal control subjects (10). 


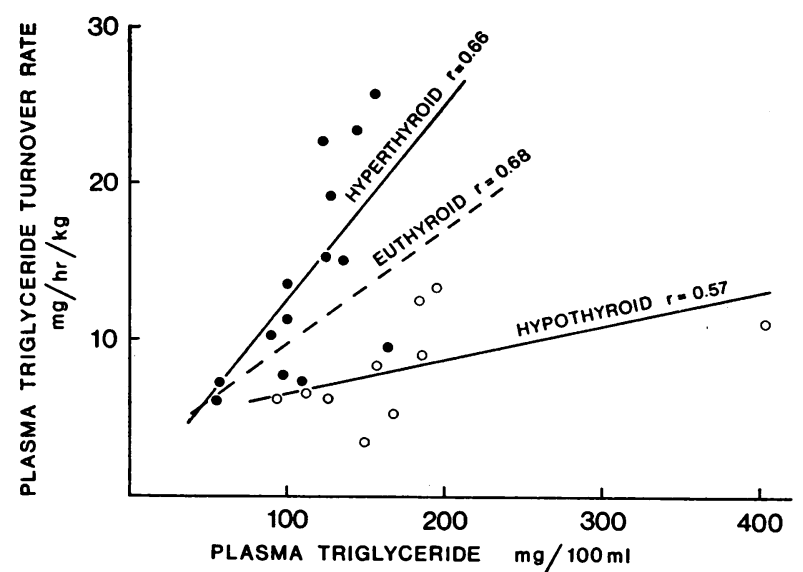

FIGURE 2 Plot of plasma triglyceride concentration against triglyceride turnover (production) rate in hyperthyroid (black dots) and hypothyroid (circles) subjects. The individual values for the euthyroid normal control group are not shown here but the regression is significant at $P<0.01$ level (10). The apparently linear concentration/turnover relationship revealed by this plot does not imply that the regression remains linear also at higher range of concentration.

mean plasma triglyceride level was slightly but significantly elevated as compared with the normal control group. Still most of the values were well within the normal range (less than mean $\pm 2 \mathrm{SD}$ of controls). The mean triglyceride fractional removal rate of hyperthyroid patients was not significantly different from normal even though some individuals (Nos. 11, 12, 15, 16) showed high values. The average total triglyceride turnover rate in thyrotoxicosis was clearly increased over that in the normal control group. However, the values were widely scattered and some patients with moderate to severe thyroid hyperfunction showed a completely normal triglyceride turnover. The nature of the alteration of triglyceride kinetics in hyperthyroidism is further illustrated by Fig. 2, presenting a plot of triglyceride concentration vs. turnover rate in hyper- and hypothyroidism and the regression line derived from a normal series (10). It is evident that most hyperthyroid cases (10 of 14 subjects) are located above the normal line, indicating that the triglyceride concentration had increased less than predicted by the increment of production rate (the expected increase being assumed to occur along the normal line). In hyperthyroid subjects the triglyceride concentration showed a significant positive correlation with turnover rate (Table VII).

The triglyceride transport kinetics were not returned to normal after successful treatment of thyrotoxicosis and the presence of euthyroid state during several months. As is shown in Table III the triglyceride concentration increased markedly in five of the eight cases studied. This was associated with a significant reduction of fractional removal rate in four instances while in two cases the production rate of triglycerides was increased. The mean decrease of the fractional disappearance from 0.292 to $0.202 \mathrm{~h}^{-1}$ was not significant, however. The average production rate of plasma triglycerides was similar before and after treatment.

In hypothyroidism the triglyceride concentration was increased but only to a moderate extent, so that there was actually little difference between hyper- and hypothyroid subjects. There was no visible lipemia except in one subject (No. 27), who showed an opalescence of fasting plasma. The fractional rate of triglyceride flux was markedly decreased in most patients with hypothyroidism, whereas the absolute total turnover rate was within a normal range (Fig. 1). These differences were also apparent when the overweight postmenopausal female hypothyroid subjects were separately compared with a matched control group (Table V). Thus, the characteristic feature of triglyceride metabolism in hypothyroidism was a decrease in removal efficiency. This is also apparent from Fig. 2, which shows that the values of all hypothyroid patients were located below the regression line of normal euthyroid controls, i.e., these patients had a higher plasma triglyceride level than predicted from the production rate. One hypothyroid subject (No. 27) was reinvestigated after adequate substitution with thyroxine. Her triglyceride concentration fell from 402 to $140 \mathrm{mg} / 100 \mathrm{ml}$

TABLE V

Triglyceride Metabolism in Hypothyroidism: Comparison of Obese Postmenopausal Hypothyroid and Euthyroid Females

\begin{tabular}{lccccc}
\hline & Age & BW & TG concentration & $\begin{array}{c}\text { TG fractional } \\
\text { transport }\end{array}$ & TG turnover rate \\
\hline & & & $m g / 100 \mathrm{ml}$ & $\mathrm{hr}$ & $\mathrm{mg} / \mathrm{kg} / \mathrm{hr}$ \\
Hypothyroid (7) & $60.5 \pm 2.9$ & $123 \pm 16$ & $183 \pm 103$ & $0.139 \pm 0.058$ & $8.9 \pm 3.7$ \\
Euthyroid (8) & $55.9 \pm 3.5$ & $139 \pm 26$ & $134 \pm 36$ & $0.215 \pm 0.047$ & $9.5 \pm 1.9$ \\
$P$ & NS & NS & NS & $<0.01$ & NS \\
\hline
\end{tabular}




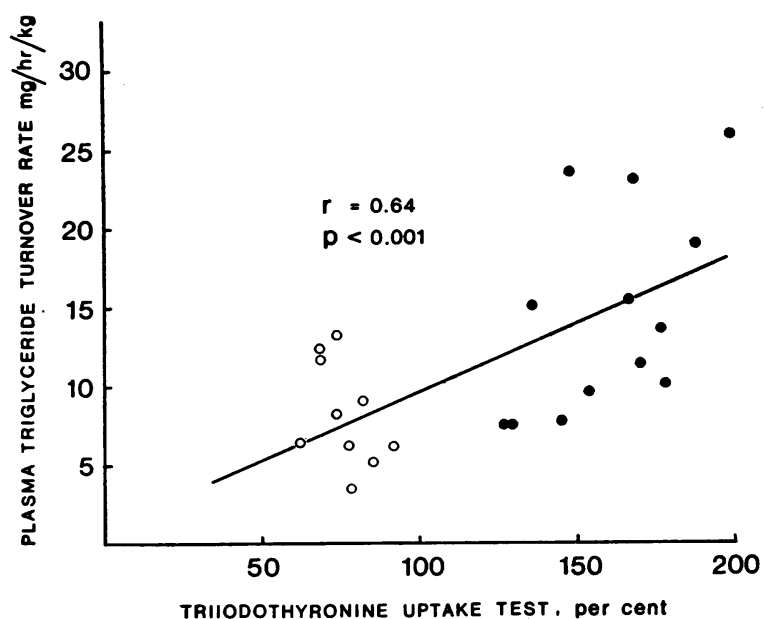

FIGURE 3 Relationship of plasma triglyceride turnover rate and T3 test in hyperthyroid (black dots) and hypothyroid (open dots) patients.

and this change was mainly accounted for by an increase in the fractional removal rate from 0.065 to 0.166 per hour.

The plasma triglyceride turnover rate showed a significant positive correlation with serum PBI and T3 in the hyperthyroid subjects as well as in the pooled hyper- and hypothyroid cases (Table VII, Fig. 3). The turnover rate was also correlated with the thyroidal radioiodine uptake in the pooled thyroid material but not in the separate groups of thyroid hyperand hypofunction (Table VII).

Removal of i.v. particulate fat. The results of the Intralipid test are illustrated in Fig. 4. The elimination

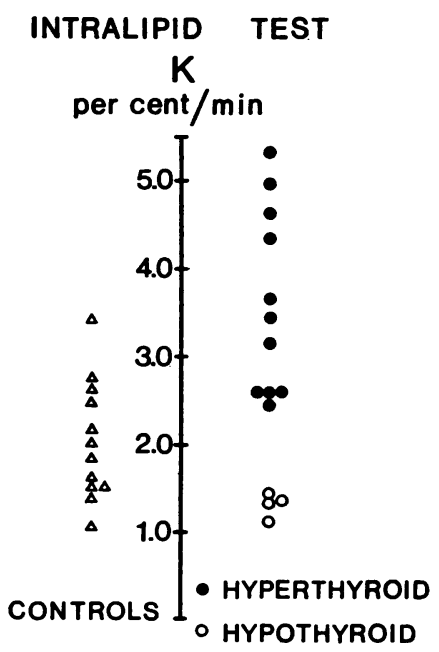

FIGURE 4 Fractional clearance rate of i.v. fat emulsion, Intralipid in patients with thyroid dysfunction as compared with euthyroid control subjects.
TABLE. VI

Plasma FFA, Glycerol, and PHLA (Mean 士SD) in Disorders of Thyroid Function

\begin{tabular}{|c|c|c|c|}
\hline & FFA & Glycerol & PHLA \\
\hline & Amoles & Amoles & $\begin{array}{c}n \text { nmoles } \\
F F A / \operatorname{ml} / \min \end{array}$ \\
\hline Controls & $510 \pm 113(43)$ & $72 \pm 32(15)$ & $181 \pm 45$ \\
\hline $\begin{array}{l}\text { Hyperthyroid } \\
\text { Untreated } \\
\text { Treated }\end{array}$ & $\begin{array}{l}957 \pm 438(15)^{*} \\
697 \pm 249(8)\end{array}$ & $\begin{array}{l}162 \pm 60(15)^{*} \\
113 \pm 50(8)\end{array}$ & $\begin{array}{c}240 \pm 70(11) \ddagger \\
-\end{array}$ \\
\hline Hypothyroid & $378 \pm 146(10) \ddagger$ & $61 \pm 29(10)$ & $68 \pm 27(6)^{*}$ \\
\hline
\end{tabular}

The figures in parentheses show the number of cases studied.

* $P<0.001$ for the difference from control group.

$\ddagger P<0.05$ for the difference from control group.

of infused triglycerides from the blood stream was clearly accelerated in thyrotoxicosis and retarded in hypothyroid subjects with little overlapping of the values of the two thyroid groups and those of the euthyroid control subjects. Because of the slow fat removal in hypothyroid patients many tests in this group failed to give an adequate exponential slope and therefore the number of successful experiments in this category remained small. There was no significant correlation between the Intralipid fractional rate constant and the three parameters of endogenous plasma triglyceride metabolism (Table VII) but the correlation coefficients for $K$-value vs. endogenous triglyceride concentration and turnover rate were both close to the border of significance.

Postheparin plasma lipolytic activity. The mean plasma PHLA was increased in the untreated hyperthyroid state and decreased in hypothyroidism (Table VI). However, there was no correlation between the

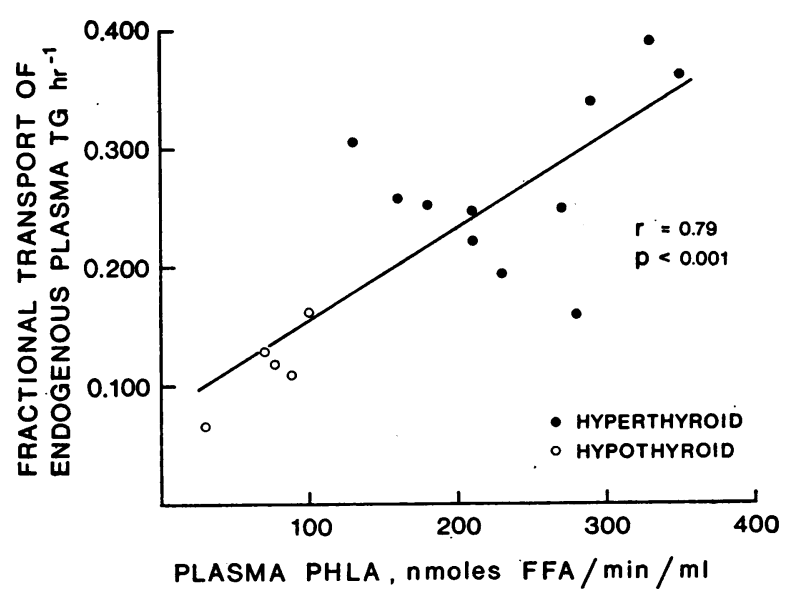

FIGURE 5 Correlation of fractional removal rate of endogenous plasma triglyceride and postheparin plasma lipolytic activity in patients with thyroid disease. 
TABLE VII

Correlations of Some Parameters of Triglyceride Metabolism

\begin{tabular}{|c|c|c|c|c|}
\hline No. & $x$ & $y$ & $r$ & $P$ \\
\hline \multicolumn{5}{|c|}{ Hyperthyroid subjects } \\
\hline 14 & TG concentration & TG turnover rate & 0.66 & $<0.01$ \\
\hline 14 & TG concentration & TG fractional transport & 0.16 & NS \\
\hline 14 & TG turnover rate & Age & 0.50 & NS \\
\hline 14 & TG turnover rate & Serum PBI & 0.53 & $<0.05$ \\
\hline 13 & TG turnover rate & T3 test & 0.56 & $<0.05$ \\
\hline 9 & TG turnover rate & Radioiodine uptake & 0.10 & NS \\
\hline 14 & FFA concentration & TG turnover rate & 0.06 & NS \\
\hline 13 & Glycerol concentration & TG turnover rate & 0.14 & NS \\
\hline \multicolumn{5}{|c|}{ Hypothyroid subjects } \\
\hline 10 & TG concentration & TG turnover rate & 0.57 & NS \\
\hline 10 & TG concentration & TG fractional transport & -0.48 & NS \\
\hline 10 & TG turnover rate & Serum PBI & 0.27 & NS \\
\hline 10 & TG turnover rate & T3 test & 0.08 & NS \\
\hline 10 & TG turnover rate & Radioiodine uptake & 0.57 & NS \\
\hline \multicolumn{5}{|c|}{ All thyroid patients } \\
\hline 24 & TG concentration & TG turnover rate & 0.18 & NS \\
\hline 24 & TG concentration & TG fractional transport & -0.44 & $<0.05$ \\
\hline 24 & TG turnover rate & Serum PBI & 0.60 & $<0.01$ \\
\hline 23 & TG turnover rate & T3 test & 0.64 & $<0.001$ \\
\hline 18 & TG turnover rate & Radioiodine uptake & 0.55 & "* $<0.05$ \\
\hline 22 & FFA concentration & TG turnover rate & 0.30 & NS \\
\hline 17 & Glycerol concentration & TG turnover rate & 0.16 & NS \\
\hline 17 & Glycerol concentration & FFA concentration & 0.82 & $<0.001$ \\
\hline 11 & Intralipid $K$-value & TG concentration & -0.53 & NS \\
\hline 11 & Intralipis $K$-value & TG fractional transport & 0.08 & NS \\
\hline 11 & Intralipid $K$-value & TG turnover rate & -0.42 & NS \\
\hline 10 & Intralipid $K$-value & PHLA & 0.45 & NS \\
\hline 16 & PHLA & TG concentration & -0.47 & NS \\
\hline 16 & PHLA & TG fractional transport & 0.79 & $<0.001$ \\
\hline
\end{tabular}

plasma triglyceride concentration and PHLA in the combined thyroid group. On the other hand, PHLA showed a highly significant correlation with the fractional rate constant of endogenous plasma triglyceride (Fig. 5), whereas the correlation with the elimination rate of exogenous triglyceride did not reach the limit of significance (Table VII).

Plasma FFA and glycerol. The mean fasting plasma FFA level was markedly increased in untreated thyrotoxicotic subjects and slightly reduced in hypothyroid patients (Table VI). In the former group the value decreased on treatment, even though it did not reach the normal level. Basal plasma glycerol concentration was also clearly above normal in thyrotoxicosis but was not significantly altered by hypothyroidism (Table VI). In a mixed group of all thyroid patients the glycerol and FFA levels were closely correlated with each other but they showed no relationship to any of the parameters of endogenous triglyceride transport (Table VII).

\section{DISCUSSION}

The results of the present study suggest that thyroid hormones influence both production and removal of plasma triglycerides in man. In the hyperthyroid state the main alteration is increased synthesis of endogenous plasma triglycerides. This leads to an elevation of plasma triglyceride concentration, which is relatively slight, however, since the efficiency of triglyceride elimination is simultaneously increased. In thyroid hypofunction, on the other hand, slight or moderate hypertriglyceridemia develops as a result of impaired removal of endogenous triglycerides, and the elimination of exogenous fat particles is also decreased.

The mechanisms responsible for these kinetic changes are not clear, but in view of the multiple metabolic actions of thyroid hormones there are a number of possible explanations for the enhanced hepatic synthesis and release of VLDL-triglycerides in thyrotoxicosis. It has been demonstrated repeatedly that in clinical and 
experimental hyperthyroidism the turnover rate and plasma concentration of FFA $(9,24-27)$ and glycerol (28) are both markedly increased, evidently due to activation of adenyl cyclase (29) and concomitant stimulation of lipolysis in adipose tissue $(30,31)$ by thyroid hormones. These findings are well supported by the results of the present study. High plasma concentrations of both FFA and glycerol, on the other hand, are effective stimulators of hepatic VLDL-triglyceride synthesis and release. A second factor acting in the same direction is enhancement of hepatic fatty acid synthesis by thyroid hormones (32-34). It has been shown that the release of triglycerides by an isolated perfused rat liver is closely related to the rate of de novo fatty acid synthesis (35). Furthermore, there are reasons for assuming that the synthesis of VLDLapoproteins is also stimulated by thyroid hormones. Thus, it is known that thyroxine increases the hepatic protein synthesis in vivo (32) and in vitro (36) and that the production of plasma albumin $(37,38)$ and of LDL (39) are elevated in hyperthyroidism. It is possible that these changes are related to the hepatic hypertrophy induced by excess of thyroid hormones. Additional factors which also might contribute to the increased hepatic secretion of triglycerides in hyperthyroidism are hyperglycemia and excessive insulin response. Several studies have indicated that elevated fasting blood glucose and impaired glucose tolerance are frequently observed in patients with thyrotoxicosis $(8,40,41)$ and the presence of hyperinsulinism in this disease has been recently reported (8). Both hyperglycemia and high plasma insulin levels are believed to stimulate the synthesis of endogenous plasma triglycerides (for review see reference 42 ).

It is not known whether an increased hepatic blood flow influences the secretion of triglycerides by the liver. The absolute rate of blood flow through the liver is increased in hyperthyroidism, even though the fraction of the cardiac output received by the liver is not changed $(43,44)$. It is not certain, however, that this factor increases the release of triglycerides from the liver and it is not impossible that the relative oxygen deficit observed in the liver in thyrotoxicosis (45) may even partially inhibit triglyceride and lipoprotein synthesis.

The fractional removal rate of endogenous plasma triglycerides in hyperthyroid patients was not significantly different from the corresponding value in normal subjects, but the rate constant $K$ of intravenously administered exogenous particulate fat was clearly increased in hyperthyroidism. On comparison of the triglyceride concentration and production rate (Fig. 2) it is evident that major part of the hyperthyroid patients had a smaller concentration than ex- pected on the basis of production rate if the relationship of these two variables in a normal population is used as reference basis. This means that in some thyrotoxic subjects, at least, the removal efficiency of endogenous triglycerides is also increased. This postulate is further supported by the observation in the present study that on transition from the hyperthyroid to the euthyroid state the fractional removal of endogenous triglycerides was decreased in most instances.

Accelerated removal of plasma triglycerides in thyrotoxicosis could be accounted for by an increased activity of lipoprotein lipase or by an increased rate of blood flow at active removal sites or both. The present study indicated that the lipolytic activity of postheparin plasma was slightly above normal in thyrotoxic subjects, but this may have been due to enhanced liberation of the enzyme into the circulation by heparin rather than to an actual increase of tissue activity. In a parallel study made in our laboratory it was observed that administration of thyroxine to rats diminishes the lipoprotein lipase activity of adipose tissue. ${ }^{2}$ A more important factor for the removal process might be the blood flow, which is known to be much increased in skeletal muscle (46) and skin (45) in thyrotoxicosis. Both of these tissues (subcutaneous adipose tissue) are probably important loci in triglyceride removal. In this connection it is of interest that another state with increased muscular perfusion, viz. exercise, is also accompanied by enhanced removal of exogenous triglycerides from the circulation (47).

The present results on the kinetic behavior of plasma triglycerides in the hyperthyroid state are at variance with the data of Sandhofer, Sailer, and Braunsteiner (9), who found decreased formation and unaltered clearance of plasma triglycerides in thyrotoxicosis. However, they used the conversion of radioactivity from plasma FFA into plasma triglyceride as the measure of triglyceride production, without correction for the fraction removed during the experiment. This method yields erroneously low values for production rate even in a normal state (48) and the extent of the error is further accentuated on increase of the fractional removal rate. Furthermore, the method using FFA incorporation rate for estimation of triglyceride turnover does not take into account the fractions of triglyceride which originate from slow intrahepatic fatty acid pathways and de novo fatty acid synthesis.

One of the most interesting and unexpected findings of the present study was the increase of plasma triglyceride concentration that often followed successful treatment of thyrotoxicosis. Although the number of cases with a follow-up study was small, it seems justi-

\footnotetext{
tion.

${ }^{2}$ Pykälistö, O., and E. A. Nikkilä. Manuscript in prepara-
} 
fied to suggest that when transition from the hyperthyroid state to clinical and hormonal euthyroidism is achieved, the production of plasma triglycerides tends to remain at a supernormal level, while the elimination of triglycerides from the circulation is diminished and leads to development of hypertriglyceridemia. It thus seems likely that many metabolic (and morphological?) consequences of a chronic hyperthyroid state are not alleviated in line with the decrease of circulating thyroid hormone but persist for months after the latter has been returned to normal (or are not reversible at all). A similar persistent triglyceride overproduction has been observed after cessation of chronic oral contraceptive treatment (49).

The changes of triglyceride metabolism in hypothyroidism are not the exact opposite of those occurring in thyrotoxicosis. Hepatic triglyceride production was not diminished in severely hypothyroid subjects even though the plasma FFA levels were slightly less than in normal controls. This latter finding conforms with the observations on decreased sensitivity of adipose tissue of hypothyroid animals to lipolytic agents (30, $50,51)$. The fact that the hepatic triglyceride output is not clearly decreased in spite of decreased concentrations of thyroid hormones and FFA may indicate that plasma triglyceride production is not absolutely dependent on the presence of thyroid hormones and is not sensitive to variations of plasma FFA at low concentration range.

The biochemical or hemodynamic basis of the deficient triglyceride removal in hypothyroidism remains to be determined. However, the close association observed here between the endogenous triglyceride fractional transport and the plasma PHLA in extreme cases of thyroid hyper- and hypofunction suggests that thyroid hormone is important for the synthesis of lipoprotein lipase and that the latter plays a central role in the elimination of. triglyceride particles of any size. This conclusion is also well supported by previous findings $(5,7)$ and by the observed variations in elimination of exogenous fat particles. On the other hand, one should not overlook the possibility that the rate of circulation might be a common factor for both the triglyceride removal process and the release of lipolytic activity by heparin. In any case, demonstration of a correlation between these parameters is possible only with extreme cases, represented here by patients from both ends of the scale of thyroid function.

Addendum. Since this paper was submitted for publication Arons, Schreibman, Downs, Braverman, and Arky (52) reported a study of PHLA activity in Graves' disease. They found a decrease of both PHLA and postheparin monoglyceridase activity in 10 patients with untreated Graves' disease. The values remained at a subnormal level also after successful treatment of the hyperthyroidism. Thyroid hor- mones administered to euthyroid subjects did not reduce the PHLA.

We have no explanation for the discrepancy between above results and those obtained in the present study. One possibility is that the patients of the New England study had a more severe thyroid hyperfunction than the present ones but a comparison in this respect is not possible since no clinical or laboratory data were reported. In our series the patient with the most severe thyrotoxicosis (No. 08) had PHLA level less than normal mean -1 sD.

\section{ACKNOWLEDGMENTS}

The authors wish to thank Dr. B-A. Lamberg, Professor of Endocrinology, for his expert advice in thyroidology and Mrs. Taru Wiherheimo, Miss Sirkka-Liisa Toikka, and Miss Hannele Suurinkeroinen for excellent technical assistance.

This work was supported by grants from Sigrid Jusélius Foundation, Helsinki, Finland, and The Finnish State Medical Research Council.

\section{REFERENCES}

1. Peters, J. P., and E. B. Man. 1950. The significance of serum cholesterol in thyroid disease. J. Clin. Invest. 29: 1 .

2. Furman, R. H., R. P. Howard, K. Lakshmi, and L. N. Norcia. 1961. The serum lipids and lipoproteins in normal and hyperlipidemic subjects as determined by preparative ultracentrifugation. Effects of dietary and therapeutic measures. Changes induced by in vitro exposure of serum to sonic forces. Am. J. Clin. Nutr. $9: 73$.

3. O'Hara, D. D., D. Porte, Jr., and R. H. Williams. 1966. The effect of diet and thyroxin on plasma lipids in myxedema. Metab. (Clin. Exp.). 15: 123.

4. Sandhofer, F., S. Sailer, and H. Braunsteiner. 1966. Plasmalipide bei Störungen der Schilddrüsenfunktion des Menschen. Klin. Wochenschr. 44: 433.

5. Kirkeby, K. 1968. Post heparin plasma lipoprotein lipase activity in thyroid disease. Acta Endocrinol. 59: 555.

6. Malmros, H., and B. Swahn. 1953. Lipid metabolism in myxedema. Acta Med. Scand. 145: 361.

7. Porte, D. Jr., D. D. O'Hara, and R. H. Williams. 1966. The relation between postheparin lipolytic activity and plasma triglyceride in myxedema. Metab. (Clin. Exp.). 15: 107.

8. Doar, J. W. H., T. C. B. Stamp, W. Wynn, and T. K. Audhya. 1969. Effects of oral and intravenous glucose loading in thyrotoxicosis. Studies of plasma glucose, free fatty acid, plasma insulin, and blood pyruvate levels. Diabetes. 18: 633.

9. Sandhofer, F., S. Sailer, and H. Braunsteiner. 1966. Fettsäure- und Triglyceridumsatz bei Schilddrüsenüberfunktion. Klin. Wochenschr. 44: 1389.

10. Nikkilä, E. A., and M. Kekki. 1971. Polymorphism of plasma triglyceride kinetics in normal human adult subjects. Acta Med. Scand. 190: 49.

11. Farquhar, J. W., R. C. Gross, R. M. Wagner, and G. M. Reaven. 1965. Validation of an incompletely coupled two-compartment non-recycling catenary model 
for turnover of liver and plasma triglyceride in man. J. Lipid Res. 6: 119.

12. Havel, R. J. 1969. Triglyceride and very low density lipoprotein turnover. In Proceedings of the 1968 Deuel Conference on Lipids. G. Cowgill, D. L. Estrich, and P. D. Woods, editors. Superintendent of Documents, U. S. Government Printing Office, Washington, D. C. 115.

13. Havel, R. J., J. P. Kane, E. O. Balasse, N. Segel, and L. V. Basso. 1970. Splanchnic metabolism of free fatty acids and production of very low density lipoproteins in normotriglyceridemic and hypertriglyceridemic humans. J. Clin. Invest. $49: 2017$.

14. Porte, D. Jr., and E. L. Bierman. 1969. The effect of heparin infusion on plasma triglyceride in vivo and in vitro with a method for calculating triglyceride turnover. J. Lab. Clin. Med. 73: 631 .

15. Nikkilä, E. A., and M. Kekki. 1971. Measurement of plasma triglyceride turnover in the study of hyperglyceridemia. Scand. J. Clin. Lab. Invest. 27: 97.

16. Alexander, J. K., E. W. Dennis, W. G. Smith, K. H. Amad, W. C. Duncan, and R. C. Austin. 1962. Blood volume, cardiac output and distribution of systemic blood flow in extreme obesity. Cardiovascular Research Bulletin (Baylor University). 1: 39. Quoted in: Medical Physiology. 1968. V. B. Mountcastle, editor. The C. V. Mosby Co., St. Louis, Mo. 1: 250.

17. Documenta Geigy. Wissenschaftliche Tabellen. 1960. 6th edition, Geigy, Basel.

18. Gibson, J. G., and A. W. Harris. 1939. Clinical studies of the blood volume. V. Hyperthyroidism and myxedema. J. Clin. Invest. 18: 59.

19. Boberg, J., L. A. Carlson, and D. Hallberg. 1969. Application of a new intravenous fat tolerance test in the study of hypertriglyceridaemia in man. J. Atheroscler. Res. 9 : 159.

20. Boberg, J., and L. A. Carlson. 1964. Determination of heparin-induced lipoprotein lipase activity in human plasma. Clin. Chim. Acta. 10: 420.

21. Kessler, G., and H. Lederer. 1966. Fluorometric measurement of triglycerides. Automat. Anal. Chem. Technicon Symp. 341.

22. Novak, M. 1965. Colorimetric ultramicro method for the determination of free fatty acids. J. Lipid Res. 6: 431.

23. Laurell, S., and G. Tibbling. 1966. An enzymatic fluorometric micromethod for the determination of glycerol. Clin. Chim. Acta. 13: 317.

24. Rich, C., E. L. Bierman, and I. L. Schwartz. 1959. Plasma nonesterified fatty acids in hyperthyroid states. J. Clin. Invest. $38: 275$.

25. Marks, B. H., I. Kiem, and A. G. Hills. 1960. Endocrine influences on fat and carbohydrate metabolism in man. I. Effect of hyperthyroidism on fasting serum nonesterified fatty acid concentration and on its response to glucose ingestion. Metab. (Clin. Exp.) 9: 1133.

26. Harlan, W. R., J. Laszlo, M. D. Bogdonoff, and E. H. Estes, Jr. 1963. Alterations in free fatty acid metabolism in endocrine disorders. I. Effect of thyroid hormone. J. Clin. Endocrinol. Metab. 23: 33.

27. Eaton, R. P., D. Steinberg, and R. H. Thompson. 1965. Relationship between free fatty acid turnover and total body oxygen consumption in the euthyroid and hyperthyroid states. J. Clin. Invest. 44: 247.

28. Tibbling, G. 1969. Glycerol turnover in hyperthyroidism. Clin. Chim. Acta. $24: 121$.
29. Krishna, G., S. Hynie, and B. B. Brodie. 1968. Effects of thyroid hormones on adenyl cyclase in adipose tissue and on free fatty acid mobilization. Proc. Natl. Acad. Sci. U.S.A. 59: 884 .

30. Debons, A. F., and I. L. Schwartz. 1961. Dependence of the lipolytic action of epinephrine in vitro upon thyroid hormone. J. Lipid Res. $2: 86$.

31. Deykin, D., and M. Vaughan. 1963. Release of free fatty acids by adipose tissue from rats treated with triiodothyronine or propylthiouracil. J. Lipid Res. 4: 200.

32. Karp, A., and D. Stetten, Jr. 1949. The effect of thyroid activity on certain anabolic processes studied with the aid of deuterium. J. Biol. Chem. 179: 819.

33. Dayton, S., J. Dayton, F. Drimmer, and F. E. Kendall. 1960. Rates of acetate turnover and lipid synthesis in normal, hypothyroid and hyperthyroid rats. $A m$. J. Physiol. 199: 71.

34. Gompertz, D., and A. L. Greenbaum. 1966. The effects of thyroxine on the pattern of fatty acid synthesis in rat liver. Biochim. Biophys. Acta. 116: 441.

35. Windmüller, H. G., and A. E. Spaeth. 1967. De novo synthesis of fatty acid in perfused rat liver as a determinant of plasma lipoprotein production. Arch. Biochem. Biophys. $122: 362$.

36. Sokoloff, L., C. M. Francis, and P. L. Campbell. 1964. Thyroxine stimulation of amino acid incorporation into protein independent of any action on messenger RNA synthesis. Proc. Natl. Acad. Sci. U. S. A. 52: 728.

37. Rotschild, N. A., A. Bauman, R. S. Yalow, and S. A. Berson. 1957. The effects of large doses of desiccated thyroid on the distribution and metabolism of albumin${ }^{181} \mathrm{I}$ in euthyroid subjects. J. Clin. Invest. 36: 422.

38. Kekki, M. 1964. Serum protein turnover in experimental hypo- and hyperthyroidism. Acta Endocrinol. 46 (Suppl.) : 91.

39. Walton, K. W., P. J. Scott, P. W. Dykes, and J. W. L. Davies. 1965. The significance of alterations in serum lipids in thyroid dysfunction. II. Alterations of the metabolism and turnover of ${ }^{181}$ I-low-density lipoproteins in hypothyroidism and thyrotoxicosis. Clin. Sci. 29: 217.

40. Hales, C. N., and D. E. Hyams. 1964. Plasma concentration of glucose, non-esterified fatty acid, and insulin during oral glucose tolerance tests in thyrotoxicosis. Lancet. 2 : 69.

41. Lamberg, B. -A. 1965. Glucose metabolism in thyroid disease. Acta. Med. Scand. 178: 351.

42. Nikkilä, E. A. 1969. Control of plasma and liver triglyceride kinetics by carbohydrate metabolism and insulin. Adv. Lipid Res. 7 : 63.

43. Myers, J. D., E. S. Brannan, and B. C. Holland. 1950. A correlative study of the cardiac output and the hepatic circulation in hyperthyroidism. J. Clin. Invest. 29: 1069.

44. Kostamis, P., A. Kralios, J. Darsinos, K. Konstantinides, D. Binopoulos, J. Sfondouris, and B. Malamos. 1968. Bestimmung der Leberdurchblutung bei Hyperthyreose nach der Extraktionsmethode von ${ }^{108} \mathrm{Au}$ aus dem Blut. Nucl. Med. Suppl. $7: 243$.

45. Grande, F., and H. L. Taylor. 1965. Adaptive changes in the heart, vessels, and patterns of control under chronically high loads. Handb. Physiol. Sect. 2. 2615.

46. Frey, H. M. M. 1967. Peripheral circulatory and metabolic consequences of thyrotoxicosis. I. Blood flow and oxygen consumption of resting and working skeletal muscle in experimental thyrotoxicosis in the dog. Scand. J. Clin. Lab. Invest. $19: 4$. 
47. Nikkilä, E. A., and A. Konttinen. 1962. Effect of physical activity on post-prandial levels of fats in serum. Lancet. 1 : 1151.

48. Havel, R. J. 1970. Metabolism of plasma triglycerides. In Atherosclerosis, Proceedings of the Second International Symposium. R. J. Jones, editor. Springer Verlag, Berlin. 210.

49. Kekki, M., and E. A. Nikkilä. 1971. Plasma triglyceride turnover during use of oral contraceptives. Metab. (Clin. Exp.). 20:878.
50. Felt, V., B. Schovanec, P. Benes, F. Plzak, and V. Vrbensky. 1962. The effect of thyroid state, adrenaline and glucose on the release of free fatty acids from adipose tissue. Experientia (Basel). 18: 379.

51. Goodman, H. M., and G. A. Bray. 1966. Role of thyroid hormones in lipolysis. Am. J. Physiol. 210: 1053.

52. Arons, D. L., P. H. Schreibman, P. Downs, L. E. Braverman, and R. A. Arky. 1972. Decreased postheparin lipases in Graves' disease. N. Engl. J. Med. $286: 233$. 